\title{
Molecular Assay of the Contamination of the Vaccinated Livestock Milk from West South of Iran: a Warning Report Against Brucellosis
}

\section{Reyhaneh Rohi', Saeideh Erfanian', Mohsen Farhang Zargar', Manouchehr Shabani', Farhad Moradi', Ali Hashempour ${ }^{1}$, Abdolreza Sotoodeh Jahromi ${ }^{1 *}$, Masoum khoshfetrat ${ }^{2}$, Mohammad Rahmdel ${ }^{3}$ \\ 'Zoonoses Research Center, Jahrom University of Medical Sciences, Jahrom, Iran \\ ${ }^{2}$ Anesthesiology Department, Iran University of Medical Sciences, Tehran, Iran \\ ${ }^{3}$ Lee Gil Ya cancer and Diabetes institute, Gachon University, School of Medicine, Incheon, South Korea.}

Study Area: Jahrom county, Fars Province, Iran

Coordinates: $28^{\circ} 30^{\prime}{ }^{\circ} " \mathrm{~N}$; $53^{\circ} 33^{\prime} 38^{\prime \prime E}$

Key words: Brucellosis, PCR, Dairy product

Project was approved by Jahrom University of Medical Sciences on January 8, 2014 with the Jums.REC.1392.051 ethics committee code.

\section{Abstract}

Brucellosis is among the most prevalent zoonoses caused by Brucella, transmitted to humans through the consumption of milk and dairy products. Currently, the Revı (sheep) and IRIBA (cow) vaccines are in use to protect the livestock from Brucella in Iran, while the diagnostic methods include the culturing and serologic methods. In this regard, the molecular polymerase chain reaction (PCR) diagnostic methods are quicker, more precise, and more sensitive than cultures, offering higher specificity than serology in the diagnosis of brucellosis. This research was an attempt at the PCR assay of the contamination of the milk from the livestock in Jahrom County, which had been vaccinated against the Brucella bacterium with the IRIBA and Rev1 vaccines. This research was a cross-sectional descriptive study carried out on 941 milk samples which were collected using the cluster random sampling technique. The Bioneer PCR Premix, Korea, was used to carry out the PCR. The overall contamination of the milk from the livestock vaccinated against the Brucella bacterium was $19 \%$. The contamination was also $18 \%$ and $20 \%$ in the livestock vaccinated with the Revi and IRIBA vaccines, respectively. The findings from this research are reflective of the presence of the Brucella species in the milk samples of the vaccinated livestock.

humans is through the intake of milkand dairy products.

The type and complications of brucellosis also vary by the bacterium transmitted from animals to humans. For instance, B. mellitensis is the most pathogenic bacterium and the most common cause of brucellosis in Iran and in the world (Higgins et al., 2017). It has shown the highest frequency and scattering in Iran in at least the past 40 years, and it is considered Iran's dominant and native biotype (Shakerian et al., 2016).

According to the World Health Organization (WHO) report, 500,000 people contract brucellosis every year, while the developed countries only account for 5 to $10 \%$ of these outbreaks. However, most of the cases are reside in the Mediterranean countries, Europe, Africa, America, Mexico, Central Asia, South Asia, and the Middle East (including Iran) (Berger, 2018). According to the $2012 \mathrm{WHO}$ report, East Azerbaijan, Hamedan, Lorestan, Markazi, South Khorasan, West Azerbaijan, and Kermanshah provinces are highly contaminated (31-41 patients per 
100,00o), while in North Khorasan, Kurdistan, and Zanjan provinces 21 to 30 patients are diagnosed in every 100,000 people (Djalalinia et al., 2018). However, it is possible to control and even eradicate this disease through regular livestock vaccination and brucellosis immunity tests (Shabu et al., 2017). The Revi (sheep) and IRIBA (cow) vaccines are used in Iran to protect the livestock from Brucella (Golshani \& Buozari, 2017). The culturing and serologic methods are available for the diagnosis of brucellosis, and despite the considerable progress and availability of the serologic tests, the main problems with these tests are obtaining the pseudo positive results (Nielsen \& Yu, 2010). In addition, these methods do not diagnose this disease in the early weeks of its onset, hence the necessity of using molecular techniques as confirmatory tests is always felt necessary (Patel et al., 2018). The molecular PCR diagnostic procedures are quicker, more precise, and more sensitive than cultures, offering higher specificity than the serologic tests in the diagnosis of brucellosis (Patel et al., 2018).

The present research goal was to conduct a PCR assay on the contamination of the milk from the livestock in Jahrom County that had been vaccinated the IRIBA and Revı vaccines.

\section{Methodology:}

This cross-sectional descriptive study was carried out in between May 2017 to February 2018 on 941 milk samples collected from Jahrom county, Fars Province, Iran. The samples were collected using the cluster technique (by dividing Jahrom county into 5 regions) and random sampling (by selecting 10 dairy farms randomly from each region). Fifty liters of milk was collected from the vaccinated livestock in the dairy farms of Jahrom County using sterilized containers. After recording the required information (including the livestock type, viz. cow or sheep, sampling location, and sampling time), the samples were immediately transferred to the laboratory with ice and were stored at a freezer at $-20^{\circ} \mathrm{C}$ until the PCR assay.

To isolate the DNAs, $500 \mu \mathrm{L}$ of each milk sample was poured into a $1.5 \mathrm{cc}$ microtube and was centrifuged at 6ooorpm for 15 minutes until the formation of three layers in the micro-tube. The upper layer contained milk fat, the middle layer consisted of a transparent liquid, and the lower layer remaining part was of the milk sediments. The transparent layer (the middle layer) was removed using a sampler, leaving the fat milk and sediments in the tubes. Further, $200 \mu \mathrm{L}$ of the TE solution (Tris-EDTA buffer) was added to the tubes and the components were mixed thoroughly. DNA extraction was done by using the phenolchloroform extraction technique, while the bacterial genome was used for tracing purposes (Kamel et al., 2014).

The Bioneer PCR Premix (Korea) was used for the PCR assay. For the study, a 223 base pair segment of a protected zone of a gene encoding an immunologic membrane protein $\left(\mathrm{BCSP}_{31}\right)$ having a molecular weight of 31 kilodaltons of Brucella abortus (belongs to the Brucella genus and is found in all Brucella biovars) was proliferated using a 21-nucleotide primer pair including $\mathrm{B}_{4}$ ( 5 ' TGG CTC GGT TGC CAA TAT CAA 3') and B5 (5'CGC GCT TGC CTT TCA GGT CTG 3'). The PCR assay involved an initial denaturation at 94 for 5 minutes and a subsequent denaturation process at 94 for 6 o seconds.

The binding took place at 60 for 60 seconds, the extension was completed at 72 for 60 seconds ( 40 cycles), and the final extension took place at 72 for 3 minutes. Agarose gel electrophoresis was also conducted to detect the proliferated segments (Patel et al., 2018). Following the electrophoresis, the gel was transferred to a transilluminator and the bands emerged on the gel under ultraviolet radiation. The PCR product was finally estimated and detected by comparing the position of the proliferated segment with the marker band sizes.

Data analysis was carried out in SPSS 16 on two descriptive statistics levels using the percentage and frequencyvalues at the 0.05 signif icance level.

\section{Results and Discussion:}

Based on the PCR test findings, the overall contamination of the milk from the livestock vaccinated with Brucella species in Jahrom dairy farms was $19 \%$. The contamination of the livestock vaccinated with Revı (sheep) and IRIBA (cow) was $18 \%$ and $20 \%$, respectively (Table-1).

Table-1: The frequency of the Brucella contamination of the milk from the vaccinated livestock in Jahrom County

\begin{tabular}{lll}
\hline PCR results & Frequency (\%) in sheep & Frequency $(\%)$ in cows \\
\hline Positive & $78(18 \%)$ & $101(20 \%)$ \\
Negative & $357(82 \%)$ & $405(80 \%)$ \\
Total & $435(100 \%)$ & $506(100 \%)$ \\
\hline
\end{tabular}

Since the main cause of transmission of brucellosis in the humans is the consumption of unpasteurized milk and dairy products and for which the livestock vaccination is one of the major preventive measures. The contamination of the milk from the livestock in Jahrom County, which had been vaccinated against Brucella, was studied through PCR assays. The presence of Brucella was conf irmed in $19 \%$ of all cow and sheep milk samples. Khalili et al. (2016) reported a Brucella prevalence of $8.3 \%$ in the milk samples in Kerman City. Through a PCR assay conducted in Kurdistan, Shafeyi et al. reported a Brucella prevalence of $33.33 \%$ and $44 \%$ in the cow and sheep milk samples, respectively (Shafei et al., 2012). In provinces such as Chaharmahal and Bakhtiari, Lorestan, and Bushehr, the prevalence of brucellosis in the cow population was $2.57,1.47$, and $1.25 \%$, respectively (Shahbazi et al., 2016). The PCR-reported prevalence of Brucella species in the milk samples in Sudan was $22.4 \%$ (Abdalla \& Hamid, 2012). In Turkey, in $2 \%$ of the whole samples the result of the PCR assay of Brucella abortus was positive (Kaynak-Onurdag et al., 2016). 
The studies by Kaynak-Onurdag et al. (2016) in Hamedan Province, Bokaie et al. (2008) in Birjand, and Roth et al. (2003) in Mongolia, Jelastopulu et al., (2008) in Greece, al-Khalaf et al. (1992) in Kuwait, and Al-Majali et al. (2007) in South Jordan also revealed that a decrease in the post-vaccination infection of livestock lowered the human infections. The result of this study indicated the presence of the Brucella species in the milk samples of even the vaccinated cows, suggesting the more possibilities for transmission of these bacteria to other livestock. Hence, the consumption of unpasteurized milk and dairy products increases the risk of Brucellosis (Khalili et al., 2016).

\section{Conclusion:}

In Iran, the livestock vaccinated with the available Brucellosis vaccines are not fully protected from this disease, as in the present research the rate of infection of the vaccinated livestock was $19 \%$. Moreover, since Brucellosis is a crucial disease with respect to economics and public health and also the WHO statistics suggest that Iran is located in a region with high frequency of Brucellosis, the proper immunization of the livestock is solely possible if at least $80 \%$ of the livestock in Iran gets vaccinated by using high-quality vaccines (Esmaeili et al., 2012). Moreover, it is recommended to value more effective vaccines such as the multiple DNA vaccines given the severe manifestations of Brucellosis and the serious threat it poses to human health.

\section{Acknowledgements:}

This research work has been supported by Jahrom University of Medical Sciences. This article is a part of Ali Hashempour's thesis.

\section{References:}

Abdalla, A. \& Hamid, M.E. (2012): Comparison of conventional and non-conventional techniques for the diagnosis of bovine brucellosis in Sudan. Trop Anim Health Prod., 44(6):1151-1155.

al-Khalaf, S.A., Mohamad, B.T. \& Nicoletti, P. (1992): Control of brucellosis in Kuwait by vaccination of cattle, sheep and goats withBrucella abortus strain 19 orBrucella melitensis strain Rev. 1. Trop. Anim. Health Prod., 24(1):45-49.

Al-Majali, A.M., Majok, A.A., Amarin, N.M. \& Al-Rawashdeh, O.F. (2007): Prevalence of, and risk factors for, brucellosis in Awassi sheep in Southern Jordan. Small Ruminant Res., 73(12):300-303.

Berger, S. (2018): Brucellosis: Global Status: 2018 edition. Pub. by: GIDEON Informatics Inc. 185p.

Bokaie, S., Sharifi, L. \& Alizadeh, H. (2008). Epidemiological Survey of Brucellosis in Human and Animals in Birjand, East of Iran. J. Anim. Vet. Adv., 7(4):46o-463.

Djalalinia, S., Arjmand, R., Gholami, M., Shaker, Y., Moghaddam, S.S., Pourrostami, K., Safari, O., Elahimehr, N., Khah, N.S. \& Zahmatkesh, E. (2018): Frequency and clinical manifestations of pediatric brucellosis in Iran: a systematic review. Int.J.Pediat., (in press)..

Esmaeili, H., Ekhtiyar, Z.H., Ebrahimzadeh, H., Partovi, R., Marhamati, K.B., Hamedi, M. \& Khaji, L. (2012): Evaluation of the national sheep and goat brucellosis control program in Iran. Arak. Med. Uni. J., 14(7):9-20.
Esmaeili, H., Esmaeili, H. \& Amiri, K. (2013): The effects of Rev-1 vaccination of sheep and goats on human brucellosis in Iran. RaziJ.Med.Sci.,107(2):20-25.

Godfroid, J., Scholz, H., Barbier, T., Nicolas, C., Wattiau, P., Fretin, D., Whatmore, A., Cloeckaert, A., Blasco, J., Moriyon, I., Saegerman, C., Muma, J.B., Al Dahouk, S., Neubauer, H. \& Letesson JJ. (2011): Brucellosis at the animal/ecosystem/ human interface at the beginning of the 21st century. Prev Vet Med., 102(2):118-131.

Golshani, M. \& Buozari, S. (2017): A review of Brucellosis in Iran: Epidemiology, Risk Factors, Diagnosis, Control, and Prevention. Iran. Biomed. J., 21(6):349-359.

Higgins, J.L., Gonzalez-Juarrero, M., \& Bowen, R.A. (2017): Evaluation of shedding, tissue burdens, and humoral immune response in goats after experimental challenge with the virulent Brucella melitensis strain $16 \mathrm{M}$ and the reduced virulence vaccine strain Rev. 1. PloS one, 12:e0185823.

Jelastopulu, E., Bikas, C., Petropoulos, C. \& Leotsinidis, M. (2008): Incidence of human brucellosis in a rural area in Western Greece after the implementation of a vaccination programme against animal brucellosis. BMC Pub. Health, 8:241.

Kamel, M., Helmy, N.A. Hafez, A.A. (2014): Different Dna Extraction Techniques from Brucella melitensis 16M. Int. J. Microbiol. Res., 5(1):69-75.

Kaynak-Onurdag, F., Okten, S. \& Sen, B. (2016): Screening Brucella spp. in bovine raw milk by real-time quantitative PCR and conventional methods in a pilot region of vaccination, Edirne, Turkey. L. Dairy Sci., 99(5):3351-3357.

Khalili, M., Aflatoonian, M.R., Aliabadi, F.S. \& Abshenas, J. (2016): Brucella contamination in raw milk by polymerase chain reaction. Tehran Uni. Med.J., 74(7):517-521.

Nielsen, K. \& Yu, W. (2010): Serological diagnosis of brucellosis. Prilozi, 31(1):65-89.

Patel, K.B., Chauhan, H., Patel, S., Patel, B. \& Chandel, B. (2018): Diagnosis of Brucella melitensis in sheep by PCR assay. Ind. J. Small Ruminants, 24(1):175-178.

Roth, F., Zinsstag, J., Orkhon, D., Chimed-Ochir, G., Hutton, G., Cosivi, O., Carrin, G. \& Otte, J. (2003): Human health benefits from livestock vaccination for brucellosis: case study. Bull. World Health Organ., 81(12):867-876.

Seleem, M.N., Boyle, S.M. \& Sriranganathan, N. (2010): Brucellosis: a re-emerging zoonosis. Vet. Microbiol.,140(3-4):392-398.

Shafei, B., Ahmadi, M., \& saei, D.H. (2012): Diagnosis of Brucella abortus and Brucella melitensis in the milk of cattle and sheep in Kordestan province by polymerase chain reaction. Vet. Res., 8(2):127-135.

Shahbazi, Y., Safavi, E-A.A. \& Shavisi, N. (2016): The epidemiological survey of animal brucellosis in Kermanshah province. Iran.J. Vet. Clin. Sci., 10(1).

Shakerian, A., Deo, P., Rahimi, E., Shahjavan, A.-R., and Khamesipour, F. (2016). Molecular detection of Brucella melitensis in sheep and goat milk in Iran. Trop. J. Pharma. Res., 15(5):913-918.

Shabu, S., Wani, H., Ali, U., Para, P.A., Ara, S. \&Ganguly, S. (2017). Brucellosis: A Current Review Update on Zoonosis. L Immunol. Immunopathol., 19(2):61-69. 